\title{
The Power of Technology in Bridge Construction Project Management
}

\author{
Fahimeh Zaeri ${ }^{\mathrm{a}}$ and \\ James Olabode Bamidele Rotimi ${ }^{\text {b }}$ \\ ${ }^{a, b}$ Construction Management Programme, \\ Auckland University of Technology, New \\ Zealand
}

fzaeri@aut.ac.nz; jrotimi@aut.ac.nz

\begin{abstract}
Bridge construction projects are inherently complex and iterative, and these place great demands on project management to apply innovative approaches for more comprehensive analysis of performance data under uncertain conditions. Although new technological-based methods such as simulation have proven to be powerful techniques to cope with cyclic and uncertain project behaviours, implementation of simulation-based modeling is below par in the construction domain especially in bridge construction. This paper presents information on significant role of recent modeling methods in the construction domain. The study is an aspect of wider research that explores capabilities of simulation-based methods in scheduling and managing of construction projects in New Zealand by considering their repetitive, uncertain and complex features. The study design and data collection are briefly described to demonstrate the power of simulation technology in bridge construction management. It is hoped that the study will benefit both construction planners and managers.
\end{abstract}

\section{Keywords}

Simulation, Bridge construction, Resource Utilization,

Uncertainty, Scheduling

\section{Introduction}

Construction projects are complex and are usually considered the most complex undertaking in any industry. The construction industry experiences great difficulty in coping with the increasing complexity of its major projects. For example complex interdependencies in a construction project's components make its analyses complicated. In addition, multiple interacting feedback processes included in a complex system such as large scale construction projects means that mental models and traditional cost and scheduling tools such as CPM do not adequately account for feedback effects [1]. Project tools such as Gantt charts, PERT (Program Evaluation and Review Technique) and CPM (Critical Path Method) have been very helpful in the scheduling of activity sequences, but are unable to solve problems related to the dynamic nature of construction projects [1]. For example, CPM-based analysis only determines the effect of a change in the time required to complete an individual step which may affect the total completion time for a project. The analyst estimates the required time on the basis of historical data, past experience or judgment. The implicit assumption is that the time required to carry out all other steps is unaffected and consequently all other interactions are ignored [1].

Further, the construction industry and academia have realized that critical path methods and other time-based methods are not suitable for repetitive projects like bridge construction, high-rise buildings, housing projects, tunnels and highways which are resource-driven in nature [2].

Sripraset and Dawood [3] are of the opinion that project failures and low productivity are due to the ineffectiveness of traditional construction planning methodologies to support today's project features. Thus, proper planning of complex project operations is important to ensure their timely and economical completion [4]. It is common knowledge that the planning phase is crucial, knowledge-intensive, illstructured, and the most challenging phase in project development cycles. More so that construction processes have become more complicated, interactive and dynamic in nature [5].

The paper reviews extant literature on simulation in construction projects and especially in bridge construction from the point of view of project scheduling, and demonstrates the applicability of simulation on a case study project. The paper is an aspect of a larger research programme which explores the potential capabilities of simulation-based modeling methods in New Zealand 
construction projects. Contextual information on the larger research on which this paper is based is provided. The information provided includes the overarching aim of the research, its objectives, and a brief description about the research methods that is being be employed to accomplish the given research objectives.

\section{Research Motivations}

Bridge construction works are associated with uncertainties that may become exacerbated by resource constraints, operational logistics and the work environment [6]. Inevitably progress on a bridge construction project is dictated by construction sequence, resource availability and structural adequacy [7]. Therefore according to Ailland et al. [8], bridge construction sites are commonly characterized by enormous pressures for time, cost and quality achievements within difficult logistic requirements.

Currently only a small number of researchers have applied simulation technology on bridge construction processes [9], while none have been applied in the New Zealand context. Although computer simulation has proven to be one of the powerful techniques for modeling uncertainties, its application in the construction domain is still limited [6]. This lack of uptake in the construction domain has generally been attributed to the difficulties associated with learning and applying simulation languages to its projects. Since the construction industry is characterized by individual products that vary in type, size, function, material and other attributes, modeling techniques would need to vary from one project to another one. Ailland et al. [8] also suggest that construction conditions change within proposed construction processes and shift as the processes progress.

Based on these characteristics, such processes create opportunities for performing comprehensive analysis using simulation techniques. Therefore, developed simulation models would need to be unique yet adaptable to varying circumstances.

The use of simulation-based tools to investigate construction process/operation has the advantage of improved modeling of construction work sequence beyond those provided by MS Project or Primavera. Both MS Project and Primavera are merely planning and scheduling tools which are limited tools for seeking the needed improvements to production outputs within the construction industry.

\section{Bridge Construction Projects}

Continuous movements of workers and machines in a linear geographic layout are involved in many construction projects such as highways, tunnels and pipelines. In this class of projects, crews parade the site one after the other during the process. These are referred to as continuous repetitive projects as opposed to discrete repetitive projects, therefore work performance cannot be measured in discrete work units, but rather continuously with certain amount of distance and time interval kept between operations [10-12].

As [13] suggest, work processes in bridge construction projects are usually linearly repetitive involving the erection of a series of abutments, piers, spans, and other segments of the bridge's superstructures Therefore, bridge construction planners need at first generate a hierarchical work breakdown structure that starts from a high-level activity, such as "Construct Bridge" and follow by lower level activities such as "Construct Abutment", "Construct Pier", and "Construct Superstructure". For each level, the planner selects and applies certain construction methods for each of those activities [14].

However, construction sequence and resource availability underpin planning progress in bridge construction projects [7]. Where, unavailability of resources has been realized as a main factor for causing uncertainties in these projects [6]. Moreover, as there is no uniform repetition of a module network in continuous repetitive projects, then traditional scheduling techniques, such as CPM (critical path method) and Gantt chart, have been criticized for their inadequacy to accurately model continuous repetitive projects [15, 16](as cited in [17]).

\section{Scheduling of Bridge Construction Projects}

Wu et al. [18] introduced scheduling of construction projects as an allocation of resources of workers, machines and materials in a time-efficient way. Moreover, baseline schedule is proposed as an important step that the contractor has to realistically estimate the duration of a project. The importance of this step is such that project owners can evaluate the feasibility of contractors based on that and also successful completion of the project is attributed to this step [19].

The differences between design, productivity of resources, availability of resources, scheduling techniques are the effective factors to make repetitive activities unique in the point of view of durations. In other words, their durations are rarely identical in each unit since those factors contribute to activity and resource schedules, and definition of the repetitive activities' characteristics. Consequently, characteristics of repetitive activities are what creates the need for sophisticated scheduling techniques and tools to schedule projects under precedence and resource constraints [2].

Further, construction project scheduling is almost experience-based. In other words, human knowledge plays an important role in project scheduling. In this point of view, previous researchers tried to capture human knowledge to create a powerful system to deal 
with scheduling issues. Which they only have been able to represent the expertise in the form of a set of data and rules on the computer [14].

Most of the previous works associated with scheduling of repetitive construction projects focus on deterministic scheduling. In this way, uncertainty, which is an inherent feature of construction projects is ignored [20].

Further, those approaches only deal with a certain degree of complication as they were limited to deterministic problems. There are few probabilistic scheduling methods that capture the stochastic nature of construction projects which employ simulation techniques. Although they attempt to take stochastic nature into account, none of them guarantees continuous resource utilization [2].

Comparison between Critical Path Method (CPM) and Discrete Event Simulation (DES) shows that simulation can provide an unbiased distribution of construction project duration. Therefore, DES methods can predict construction project duration more realistically than CPM $[21,22]$.

Although, simulation has gained acceptance as a particular scheduling tool in other fields like operations research and in the manufacturing industry, but it has not been yet popular in the construction industry. Absence of a reliable method in selecting probability distributions for construction activity duration has been realized as the fundamental reasons for the limited use of simulation as a scheduling tool in construction domain [19].

Multitude of requirements such as a technological dependencies and resource capacities should be taken into account together with principal guidelines of project duration and available funds. However, the scheduling of construction projects become more complex as $\mathrm{Wu}$ et al. [18] (2010) found constraint-based simulation could be a more proper technique. Although they have been successful to overcome intricacies associated with scheduling construction projects by generating effective schedules virtually automatically but creating the necessary input data manually has been the major drawback of these approaches [18].

\section{Resource Allocation in Bridge Construction Projects}

Traditional scheduling methods such as CPM and graphical methods like Line-Of-Balance (LOB) cannot consider dynamic and resource-driven features of construction activities [2]. It seems that mathematical methods have been successful to model behaviours of shared resources through dynamic programming but in comparison to resource-driven simulation, they cannot be so effective. In addition, some of resource-driven simulations such as STROBOSCOPE use a conditioning node (e.g. Fork node) within shared resources allocation processes which offer a great advantage in the modeling of construction activities by considering their dynamic and resource-driven feature. The way of assigning shared resources between construction activities has an important role in successfully management of continuous repetitive projects [2].

CPM, LOB and Repetitive Scheduling Method (RSM) methods assume that activities require only one resource each and resource availability constraints are modeled by using precedence constraints. In these methods, a resource serves only one activity which is called a "dedicated resource" while in reality, activities may share the same resources. Where, resources and activities are called shared resources and resource-sharing activities respectively. However, precedence constraints approaches have failed to present resource availability constraints for shared resources [2].

Resources constraints are classified into 1/ resource availability constraints, and 2/ resource continuity constraints. The first category controls the output of activities for which their resources are available during a particular period while the second one includes the resources which need to work continuously and without interruption from the time they first arrive to the job site until they leave. As Srisuwanrat [2] proposed, considering this repetitive feature is indispensable to resource allocation within scheduling a construction project.

\section{Simulation in Bridge Construction Projects}

Kim [19] described simulation as a building and investigation process for a computerised model of a system which captures various time measures such as real time, expanded and compressed time to improve the behaviour of a process or system. Simulation is able to model any system with any set of conditions in a more practical way since it runs the computerised model of a system rather than finding analytical solution. This potential of simulation makes it more advantageous than traditional scheduling methods like CPM and PERT. In other words, the considered system does not need to be analytically managed. Moreover, fewer assumptions are required when simulation is used to schedule construction projects.

In the simulation approach, individual activities, interdependencies among them and resource availability are taken into account. This capability makes simulation suitable for detailed investigation of construction schedules [18].

Although simulations have been successful their implementations have not drawn as much attention in bridge construction processes.

Few examples of studies that have applied simulation within the bridge construction domain include works done by Ailland et al. [8], AbouRizk and Dozzi [23], [24], [25] and [26]. In their work, AbouRizk and Dozzi [23] used CYCLONE to facilitate dispute resolution in 
bridge jacking operations. Huang and Halpin [24] simulated the construction operations in a cable-stayed bridge in Washington by using DISCO simulation software. Chan et al. [25] used SDESA to simulate field processes for a pre-cast bridge, resulting in optimal solutions to the pre-cast segment inventory problems.

Others like Marzouk [6] utilized simulation model like STROBOSCOPE as a simulation engine which was coded by Visual basic 6.0 to develop a special purpose simulation model to assist in the planning of bridge deck construction. This simulation engine considers uncertainties and the interaction amongst resources used for the construction works. Marzouk et al [6] had modelled the 15th May Bridge located in Cairo, Egypt which was constructed using an incremental launching technique. Marzouk et al [6] examined the results of the developed model and illustrate its capabilities in modeling two construction methods; single form, and multiple form. A sensitivity analysis was performed in their study to evaluate the performance of the system under different combination of resources. The study eventually enabled planners to estimate duration and production rate in each combination within those different methods of bridge construction and also provided them more understandable results to study the impact of assigned resources when estimating project duration.

Another research study undertaken on bridge construction by Said et al [27], reflects how simulation can facilitate construction process planning. Said et al had employed a developed STROBOSCOPE simulation engine, called 'Bridge-Sim' in a case study of the ElWarrak Bridge in Cairo - Egypt, to estimate the total duration of deck execution and the associated total costs. Said et al [27] suggests that Bridge-Sim also enables planners and contractors to evaluate different scenarios of construction plant utilization which represents various combinations of construction methods, crew formations, and construction sequencing. For example they compared cast-in-place on falsework method and cantilever carriage construction methods for the El-Warrak bridge. Simulating of the two construction process methods demonstrated the potent capabilities of simulation method in the creation of comprehensive documentation systems that helps planners in analysing construction alternatives where the project involves many repetitive activities, complex interdependencies between construction resources and uncertainties.

Table.1 presents information on typical construction projects where, how and /why simulation was implemented on a variety of projects.

Simulation modeling methodologies vary depending on the nature of the projects to be modeled, but it could be observed from the table, that simulation is applicable to a wide spectrum of construction operations [28].

Simulation can be applied in general or for special purposes. General purpose simulation (GPS) refers to the formulation of a simulation model for a system underinvestigation, running the simulation and analysing the results to decide whether the system is acceptable or not. If it is not acceptable, the process would need to be reiterated and an alternative system considered. Various GPS software systems have been developed for a wide range of industries e.g. AweSim [29] and GPSS/H [30], and for construction: Micro-CYCLONE [5] and STROBOSCOPE [31]. Special purpose simulation (SPS), on the other hand, is developed for a specific domain of application through the creation of a definite platform or template [32, 33]. The steps for simulation are the same in both GPS and SPS except the first step (involving the construction of the simulation model) where the platform includes the characteristics and behaviour of the considered system in SPS. Also, the modification is limited to the input parameter(s) of a pre-defined system and not to the characteristics and behaviour of the system [6].

It is conclusive from the foregoing that simulation is an appropriate tool to support construction planning, reducing the risks associated with time, budget, and quality and also increases productivity and operational efficiency [34].

\section{Design of the Research Study}

The section describes aspects of the larger study programme (doctoral research project) on which the current study is based. The study is at a relatively early stage in New Zealand. The main objective of the doctoral research is to determine how simulation methods could improve construction projects performance and productivity. The study is expected to provide some general and specific benefits for the NZ's construction sector as outlined below:

(i) General

1. The development of an object-oriented framework for modeling construction operations toward improving projects productivity. This will contribute to current industry initiatives for productivity improvement by $20 \%$ in 2020.

2. Providing a general understanding of the features of simulation modeling at functional/operational levels of construction management as a complementary tool to planning and analysing complex construction projects.

\section{(ii) Specific}

1. Complement existing project planning methodologies currently being used at the operational level for the case study project with simulation modeling. 
Table 1. Review on The Application of Simulation Methods in Bridge Construction Projects

\begin{tabular}{|c|c|c|c|c|}
\hline Simulation engine/software & $\begin{array}{c}\text { Simulation } \\
\text { strategy/method }\end{array}$ & Benefits & Researcher (Year) & Construction method \\
\hline Fuzzy Logic Simulation & Stochastic method & $\begin{array}{l}\text { 1- Estimate process duration } \\
\text { 2- Using sensitivity analysis to validate simulation strategy }\end{array}$ & $\begin{array}{l}\text { Ailland et al. } \\
\text { (2010) }\end{array}$ & $\begin{array}{l}\text { Using mobile scaffold, double } \\
\text { webbed t-beam cross section } \\
\text { made of pre-stressed concrete }\end{array}$ \\
\hline CYCLONE & $\begin{array}{l}\text { General Purpose } \\
\text { Simulation }\end{array}$ & Facilitate dispute resolution & $\begin{array}{c}\text { AbouRizk et al } \\
\text { (1993) }\end{array}$ & \\
\hline $\begin{array}{l}\text { DISCO (dynamic interface for } \\
\text { simulation of construction operations) }\end{array}$ & $\begin{array}{l}\text { Graphical construction } \\
\text { simulation system }\end{array}$ & $\begin{array}{l}\text { 1- Provide a graphical environment in which modeling and } \\
\text { simulation of construction operations can be conducted in an } \\
\text { interactive fashion. } \\
\text { 2- Analyze system productivity as well as resource utilization by } \\
\text { examining graphical report. }\end{array}$ & $\begin{array}{l}\text { Huang, R. et al. } \\
\text { (1994) }\end{array}$ & $\begin{array}{l}\text { segmental balanced cantilever } \\
\text { technique to build on both sides } \\
\text { of the pylon at the same } \\
\text { time }\end{array}$ \\
\hline $\begin{array}{l}\text { SDESA(Simplified Discrete Event } \\
\text { Simulation) }\end{array}$ & $\begin{array}{l}\text { General Purpose } \\
\quad \text { Simulation }\end{array}$ & $\begin{array}{l}\text { Simulate field processes to reach optimal solutions to the pre-cast } \\
\text { segment inventory problems }\end{array}$ & Chan et al. (2005) & \\
\hline $\begin{array}{l}\text { STROBOSCOPE/Bridge-Sim } \\
\text { Software }\end{array}$ & $\begin{array}{l}\text { General Purpose } \\
\text { Simulation }\end{array}$ & $\begin{array}{l}\text { 1- Facilitate construction process planning } \\
\text { 2- Estimate the total duration of deck execution and associated total } \\
\text { cost } \\
\text { 3- Enable planners and contractor to evaluate different scenarios of } \\
\text { construction plant utilization }\end{array}$ & $\begin{array}{l}\text { Marzouk et al. } \\
(2008,2009)\end{array}$ & $\begin{array}{l}\text { Cast-in Place on Falsework and } \\
\text { Cantilever Carriage }\end{array}$ \\
\hline Pattern-Based Simulation & $\begin{array}{l}\text { Discrete Event based } \\
\text { environment and } \\
\text { Constraint-Based strategy/ } \\
\text { Preparator }\end{array}$ & $\begin{array}{l}\text { 1- It consists of a sequence of work packages for realizing standard } \\
\text { bridge parts which allows user to specfy the available resources } \\
\text { 2- Facilitate schedule generation and cost analysis in bridge } \\
\text { construction projects } \\
\text { 3- Encapsulate the repetitive construction processes } \\
\text { 4- Guaranty a high flexibility in modelling processes }\end{array}$ & $\begin{array}{l}\text { Wu, IC } \\
\text { et al. } \\
(2009)\end{array}$ & \\
\hline SimoFit & $\begin{array}{l}\text { Discrete Event based } \\
\text { environment and } \\
\text { Constraint-Based Strategy }\end{array}$ & $\begin{array}{l}\text { 1- Deliver important data for construction simulation based on } \\
\text { existing huge data sources (data source is the base of high level } \\
\text { simulation solutions.) } \\
\text { 2- The construction tasks and their constraints for production such } \\
\text { as technological dependencies, availability and capacity can be } \\
\text { specified and valid execution schedules can be generated. } \\
\text { 3- Developed simulation models to investigate the impact of } \\
\text { different influencing parameters on the performance of construction } \\
\text { activities. }\end{array}$ & $\begin{array}{c}\text { - Melzner et al. } \\
\text { (2011) }\end{array}$ & \\
\hline
\end{tabular}


2. Enhancing decision making on construction process strategy because when the model is developed, it could be used for planning and analyses of a wide range of construction processes.

3. The case study organization could adopt the simulation tool as a best practice approach to analysing and planning for the execution of their complex projects. The workshops planned at every stage of the model development could serve as capacity building workshops for operations personnel.

Information will be gathered from a case study investigation and will be complemented with semistructured interviews and focus group studies. The case study envisaged by the research is a bridge construction project which is at an early stage of development in Auckland - New Zealand. The project involves the erection of four ramps using Self-Lunching Twin Truss Gantry construction technique.

\section{Conclusion}

Dealing with repetitive, uncertain, and dynamic features of construction projects within scheduling methods have been sources of concern in the construction domain. To achieve accuracy and /successful management of construction projects, then planners need to implement better modeling methods. Regarding the ineffectiveness of traditional planning methods, project planners would need to seek integrated approaches using new technologies in construction management.

Considering that there have been fewer studies related to implementation of simulation in this domain the current study thus finds its usefulness. The study represents an innovative holistic study within the NZ construction sector that would deal with intricacies involved in construction projects management and help improve projects' delivery.

\section{References}

1. Sterman, J.D., System dynamics modeling for project management. Unpublished manuscript, Cambridge, MA, 1992.

2. Srisuwanrat, C., The Sequence Step Algorithm: A simulation-based scheduling algorithm for repetitive projects with probabilistic activity durations, 2009, ProQuest, UMI Dissertations Publishing.

3. Sriprasert, E. and N. Dawood. Next generation of construction planning and control system: the LEWIS approach. in EWork and EBusiness in Architecture, Engineering and Construction: Proceedings of the Fourth European Conference on Product and Process Modelling in the Building and Related Industries, Portorož, Slovenia, 9-11 September 2002. 2002. Taylor \& Francis. 4. Puri, V., Incorporation of continuous activities into activity cycle diagram based discrete event simulation for construction operations, 2012, ProQuest, UMI Dissertations Publishing.

5. Halpin, D.W. and L.S. Riggs, Planning and Analysis of Construction Operations,. John Wiley and Sons, Inc., New York, N.Y., 1992: p. 381.

6. Marzouk, M., H.Z. El-Dein, and M. El-Said, Application of computer simulation to construction of incremental launching bridges. Journal of Civil Engineering and Management, 2007. 13(1): p. 27-36. 7. Chan, W.-H. and M. Lu. Construction operations simulation under structural adequacy constraints: the Stonecutters Bridge case study. in Simulation Conference (WSC), Proceedings of the 2012 Winter. 2012. IEEE. 8. Ailland, K., H.-J. Bargstädt, and S. Hollermann. Construction process simulation in bridge building based on significant day-to-day data. in Proceedings of the Winter Simulation Conference. 2010. Winter Simulation Conference.

9. $\quad \mathrm{Wu}, \mathrm{I}$.C., et al., Bridge construction schedule generation with pattern-based construction methods and constraint-based simulation. Advanced Engineering Informatics, 2010. 24(4): p. 379-388.

10. Yamín, R.A. and D.J. Harmelink, Comparison of linear scheduling model (LSM) and critical path method (CPM). Journal of Construction Engineering and Management, 2001. 127(5): p. 374-381.

11. Georgy, M.E., Evolutionary resource scheduler for linear projects. Automation in Construction, 2008. 17(5): p. 573-583.

12. Yang, I.-T. and P.G. Ioannou, Scheduling system with focus on practical concerns in repetitive projects. Construction Management \& Economics, 2004. 22(6): p. 619-630.

13. Hsie, M., et al., Resource-constrained scheduling for continuous repetitive projects with time-based production units. Automation in Construction, 2009. 18(7): p. 942-949.

14. Wu, I., et al. A pattern-based approach for facilitating schedule generation and cost analysis in bridge construction projects. in Proc. of the 26th CIBW78 Conference on Managing IT in Construction. 2009. 15. Vorster, M., Y.J. Beliveau, and T. Bafna, Linear scheduling and visualization. Transportation Research Record, 1992(1351).

16. Lucko, G., Productivity Scheduling Method Compared to Linear and Repetitive Project Scheduling Methods. Journal of Construction Engineering and Management, 2008. 134(9): p. 711-720.

17. Hsie, M., et al., Resource-constrained scheduling for continuous repetitive projects with time-based production units. Automation in Construction, 2009. 18(7): p. 942-949.

18. Wu, I., et al., Bridge construction schedule generation with pattern-based construction methods and constraint-based simulation. Advanced Engineering Informatics, 2010. 24(4): p. 379-388.

19. Kim, J., An investigation of activity duration input modeling by duration variance ratio for simulation- 
based construction scheduling, 2007.

20. Bakry, I., O. Moselhi, and T. Zayed, Fuzzy

Scheduling of Repetitive Construction Projects. 2013: p. 1172 - 1176.

21. Pidd, M., Computer simulation for operational research in 1984, 1984, Pergamon Press, Oxford.

22. Paul, R.J., Recent Developments in Simulation Modelling. The Journal of the Operational Research Society, 1991. 42(3): p. 217-226.

23. AbouRizk, S.M. and S.P. Dozzi, Application of computer simulation in resolving construction disputes. Journal of construction engineering and management, 1993. 119(2): p. 355-373.

24. Huang, R., A.M. Grigoriadis, and D.W. Halpin. Simulation of cable-stayed bridges using DISCO. in Proc., 1994 Winter Simulation Conf., IEEE, Piscataway, N.J. 1994.

25. Chan, W.-H. and M. Lu. Logistics and operations simulation in precast viaduct construction: case study. in Proceedings of the 2005 ASCE International Conference on Computing in Civil Engineering. 2005.

26. Marzouk, M., H. Said, and M. El-Said, SpecialPurpose Simulation Model for Balanced Cantilever Bridges. Journal of Bridge Engineering, 2008. 13(2): p. $122-131$.

27. Said, H., M. Marzouk, and M. El-Said, Application of computer simulation to bridge deck construction: Case study. Automation in Construction, 2009. 18(4): p. 377-385.

28. Mohamed, Y. and S.M. AbouRizk, Framework for Building Intelligent Simulation Models of Construction Operations. Journal of Computing in Civil Engineering, 2005. 19(3): p. 277-291.

29. Pritsker, A.A.B. and J.J. O'Reilly, Simulation with visual SLAM and AweSim1999: Wiley. com.

30. $\quad$ Crain, R.C. Simulation using GPSS/H. in Proceedings of the 29th conference on Winter simulation. 1997. IEEE Computer Society.

31. Martinez, J.C., Stroboscope: State and resource based simulation of construction processes, 1996.

32. Marzouk, M. and O. Moselhi, Object-oriented simulation model for earthmoving operations. Journal of Construction Engineering and Management, 2003. 129(2): p. 173-181.

33. AbouRizk, S.M. and D. Hajjar, A framework for applying simulation in construction. Canadian journal of civil engineering, 1998. 25(3): p. 604-617.

34. Melzner, J., S. Hollermann, and H.-J. Bargstädt. Detailed Input data Source for Construction Process Simulation. in SIMUL 2011, The Third International Conference on Advances in System Simulation. 2011. 